\title{
Malignant Hyperthermia in Bariatric Surgery: A Case Study With Clinical, Pathophysiological, Biochemical and Biophysical Correlations
}

\author{
Pierri E.A. Oliveira ${ }^{\text {a }}$, Guilherme H.M. Salvador ${ }^{\mathrm{b}}$, Daniela P. Marchi-Salvador ${ }^{\mathrm{a}, \mathrm{c}}$
}

\begin{abstract}
Malignant hyperthermia $(\mathrm{MH})$ is an acute pharmacogenetic disorder, which while uncommon is potentially fatal. $\mathrm{MH}$ is a calcium channelopathy of skeletal muscle in which a constant increase of intracytoplasmic $\mathrm{Ca}^{2+}$ concentration occurs causing a change in cellular metabolism. A hypermetabolic state develops when susceptible patients are exposed to halogenated volatile inhalational anesthetic agents and depolarizing muscle relaxants and/or extreme physical activity in hot environments. MH presents variable clinical expression. During an episode of $\mathrm{MH}$, the patient may present clinical signs and laboratory findings including masseter muscle spasm, tachycardia, rise in endtidal $\mathrm{CO}_{2}\left(\mathrm{EtCO}_{2}\right)$, tachypnea, hyperthermia, cyanosis, metabolic acidosis, rhabdomyolysis, hyperkalemia, myoglobinuria, hyperlactacidemia, and acute renal failure. The aim of this case report is to describe an episode of $\mathrm{MH}$ associated with the use of halogenated anesthetic during bariatric surgery. A 29-year-old Brazilian man was admitted to the hospital to undergo a bariatric surgery. The patient's relevant medical history included morbid obesity grade III, allergy to sulfa-based drugs and severe obstructive sleep apnea. Preoperative evaluations with cardiopulmonary exercise testing, echocardiogram and electrocardiogram showed no anatomical and functional changes of the patient's heart. Surgical procedures lasted for $4 \mathrm{~h}$, without complications, but the evolution of the patient's condition indicated oliguria and acute breathing insufficiency. Five hours after the patient was placed under mechanical ventilation in the intensive care unit, he started to present clinical signs of hypermetabolic state, with tremors, excessive sweating, and rapid body temperature increases. In the postoperative period, the patient had hyperglycemia, hypocalcemia, hypernatremia, hyperkalemia, changes in creatine phosphokinase (CPK), aspartate transaminase (AST), alanine aminotransferase
\end{abstract}

Manuscript submitted September 2, 2020, accepted September 19, 2020

Published online October 21, 2020

aDepartamento de Biologia Molecular, CCEN, UFPB, Joao Pessoa, PB, Brazil bDepartamento de Fisica e Biofisica, Instituto de Biociencias, UNESP, Botucatu, SP, Brazil

${ }^{\mathrm{C} C}$ Corresponding Author: Daniela P. Marchi-Salvador, Universidade Federal da Paraiba (UFPB), Centro de Ciencias Exatas e da Natureza (CCEN), Departamento de Biologia Molecular (DBM), Laboratorio de Cristalografia de Proteinas (CPr-Lab), Campus I - Cidade Universitaria, Joao Pessoa, PB, 58051900, Brazil. Email: danimarchi@dbm.ufpb.br

doi: https://doi.org/10.14740/jmc3577
(ALT), urea and creatine concentrations, and metabolic and respiratory acidosis. Urinalysis showed traces of proteinuria, presence of ketones, leukocytes, red blood cells, and urobilinogen. In our case report, MH crisis was diagnosed late; the dantrolene was not administrated because it was not available and the patient died. This detailed case report of $\mathrm{MH}$ episode triggered by isoflurane anesthetic during bariatric surgery allowed us to describe the severity and lethality of this hypermetabolic syndrome. Dantrolene should be mandatory in all operating rooms. Knowledge of the symptoms, an early diagnosis and an adequate treatment can prevent the death of patients in $\mathrm{MH}$ crisis.

Keywords: Pharmacogenetic disorder; Halogenated anesthetic; Hypermetabolic state; Metabolic acidosis; High CPK concentration; Respiratory acidosis; Dantrolene sodium; Caffeine-halothane contracture test

\section{Introduction}

Malignant hyperthermia $(\mathrm{MH})$ is an acute pharmacogenetic disorder, which while uncommon is potentially fatal $[1,2]$. In humans, susceptibility to $\mathrm{MH}$ is an inherited disorder and it has an autosomal dominant pattern [3-7]. To date, genes located at six chromosomal loci associated with MH have been described: 1) Ryanodine receptor type $1(R y R l)$ gene, ryanodine receptor found in skeletal muscle (chromosomal locus 19q13.1.); 2) CACNA1S gene, which encodes for the alpha-1S subunit of dihydropyridine (chromosomal locus 1q32); 3) A variant of the STAC3 gene, which encodes an important protein for excitationcontraction coupling via trafficking the voltage sensor into the correct T-tubular location (chromosomal locus 7q21-q22); 4) $S C N 4 A$ gene (possible), related to voltage-dependent sodium channel of skeletal muscle (chromosomal locus 17q11.2-q24); and, not yet identified genes for 5) chromosomal loci 3q13.1 and 6) $5 \mathrm{p}$ [2, 5, 7-10]. However, these genes associated with $\mathrm{MH}$ show incomplete penetrance and variable expression $[4,5,7]$.

$\mathrm{MH}$ is related to muscle function and calcium levels. A muscle contraction starts when the action potential arrives at the neuromuscular junction, starting a muscle depolarization and causing a conformational change in the T-tubular L-type voltage-dependent calcium channel (dihydropyridine calcium channel receptor, DHPR). This conformational change activates the $R y R 1$ leading to a rapid release of $\mathrm{Ca}^{2+}$, from sar- 
coplasmic reticulum, increasing the intracytoplasmic $\mathrm{Ca}^{2+}$ concentration [5, 11-13]. Muscle relaxation occurs when stimulation of the motor nerve stops and the intracellular adenosine triphosphate (ATP)-dependent $\mathrm{Ca}^{2+}$ pump transports intracytoplasmic $\mathrm{Ca}^{2+}$ into the sarcoplasmic reticulum lumen [5, 7, $13,14] . \mathrm{MH}$ is a calcium channelopathy of skeletal muscle [15] in which a constant increase of intracytoplasmic $\mathrm{Ca}^{2+}$ concentration occurs causing a change in cellular metabolism $[5,7-9,13]$. A hypermetabolic state develops when susceptible patients are exposed to halogenated volatile inhalational anesthetic agents (halothane, isoflurane, enflurane, sevoflurane, desflurane and methoxyflurane), depolarizing muscle relaxants (e.g., succinylcholine), and/or extreme physical activity in hot environments $[3,7,8,16-18]$. The $\mathrm{MH}$ clinical incidence is estimated to be from 1 in $10,000-30,000$ to 1 in $100,000-250,000$ in patients undergoing anesthesia, depending on geographic localization and age $[6,9]$. Nevertheless, the prevalence of genetic variants or mutations of an individual susceptible to $\mathrm{MH}$ is estimated to be 1 in 2,000 - 3,000 [5, $6,10]$. MH affects all ethnic groups and both sexes, although there is a greater predisposition for men and children, and it is atypical in the elderly [3, 5-7]. The MH episode can occur both in the first exposure to the substances that triggers the crisis and in subsequent contacts $[8,19,20]$.

$\mathrm{MH}$ presents variable clinical expression $[2,5]$. During an episode of $\mathrm{MH}$, the patient may present clinical signs and laboratory findings including masseter muscle spasm, tachycardia, rise in end-tidal $\mathrm{CO}_{2}$ concentration $\left(\mathrm{EtCO}_{2}\right)$, tachypnea, hyperthermia, cyanosis, metabolic acidosis, rhabdomyolysis, hyperkalemia, myoglobinuria, hyperlactacidemia and acute renal failure $[1,3,7,8,17,21]$. When the pathology is diagnosed, the exposure to the triggering agents should be discontinued followed by immediate intravenous administration of dantrolene sodium, a hydantoin-derived skeletal muscle relaxant drug $[5,11,17,22,23]$. Dantrolene remains the drug of choice for $\mathrm{MH}$ prophylaxis and treatment $[8,11,22]$. In addition, protocols must be established to control or prevent complications associated with the clinical condition of the disease. These include external (if necessary, internal) cooling of the patient's body, hyperventilation with $100 \%$ oxygen, correction of metabolic acidosis, adjustment of cardiac arrhythmias, dialysis to remove anesthetic residues and aid in blood filtration to revert metabolites to normal levels [3, 6, 8, 9].

Several tests have been proposed or are being investigated as less invasive diagnostic tests to determinate $\mathrm{MH}$ susceptible patients [24], including: 1) Evaluation of creatine kinase concentrations; 2) In vitro measurement for the concentrations of ATP, phosphocreatine or other phosphomonoesters, along with $\mathrm{pH}$, in muscle and other tissue by nuclear magnetic resonance spectroscopy; 3) Evaluation of calcium flow at $R Y R 1$ receptors on B lymphocytes; 4) Assessment of the enhanced intracellular calcium from cultured muscle tissue; and 5) Molecular genetic tests to look for mutations in the genes associated with $\mathrm{MH}$ susceptibility. However, the caffeine-halothane contracture test (CHCT) remains the standard method used in Brazil [1, 12, 24, 25]. CHCT must be performed on a biopsy of approximately 2 $\mathrm{g}$ of muscle from the vastus lateralis or vastus medialis $[3,12$, 24]. The muscle fragment is longitudinally dissected into strips and the level of muscle contraction is assessed before and after exposure to caffeine and halothane (RYR1 agonists) [6, 24]. Individuals who are susceptible to $\mathrm{MH}$ have a CHCT positive result when abnormally high levels of contractile force are detected after the caffeine and/or halothane exposure $[6,12,24$, 26]. The aim of this case report is to describe an episode of $\mathrm{MH}$ associated with the use of halogenated anesthetic during bariatric surgery. The case study is intended to serve as inclusive knowledge and a reference tool for healthcare professionals and academic-scientific area with respect to clinical, pathophysiological, biochemical, and biophysical correlations.

\section{Case Report}

Informed consent was obtained from the patient's family as well as authorization to use and disclose protected health information. L.R.M.S was a 29-year-old man, born in Jau, Sao Paulo, Brazil but with European ascendance. He was admitted to the Hospital Santa Casa de Jahu to undergo a bariatric surgery, vertical gastroplasty to Roux-en-Y gastric bypass without a ring, using the conventional technique (not performed by laparoscopy).

The patient's relevant medical history included morbid obesity grade III, allergy to sulfa-based drugs and severe obstructive sleep apnea (i.e., apnea and hypopnea index greater than 30 hypopneas and apneas per hour). The patient complained of episodes of gastroesophageal reflux and the repeated occurrences of calf cramps. In addition, due to the obesity condition, the patient possessed a lack of energy, impaired mobility, episodes of peak hypertension, and mood changes. The patient was using antidepressant medications to treat anxiety. Preoperative evaluations with cardiopulmonary exercise testing, echocardiogram with color Doppler and electrocardiogram showed no anatomical and functional changes of the patient's heart. However, some signs of hepatic steatosis were detected from a total abdominal ultrasound and spirometry test showed a mild obstructive ventilatory defect. On pre-anesthetic evaluation, the patient reported that he had never undergone general anesthesia. Furthermore, none of his family members had presented complications in surgical procedures with general anesthesia.

Upon arriving at the operating room, the patient's preoperative blood pressure was 200/130 $\mathrm{mm} \mathrm{Hg}$ with an oxygen saturation of $94 \%$. Although the patient's oxygen saturation showed normal in the preoperative exams, while lying down a significant drop in this saturation was observed. Surgical procedures started at approximately 8 am on February 14, 2011 and ended at 12:50 pm, without complications. General anesthesia was induced and maintained with the following agents as described in Table 1.

After the end of the surgical procedures, the patient remained in the operating room for another hour until he responded to stimuli. Then, the patient was taken to the recovery room, where he stayed until $2 \mathrm{pm}$. According to medical reports, the evolution of the patient's condition indicated oliguria and acute breathing insufficiency. Therefore, the patient was placed under mechanical ventilation in the intensive care unit (ICU). 
Table 1. Anesthetics, Analgesic and Muscle Relaxant Agents Used During the Intraoperative Period

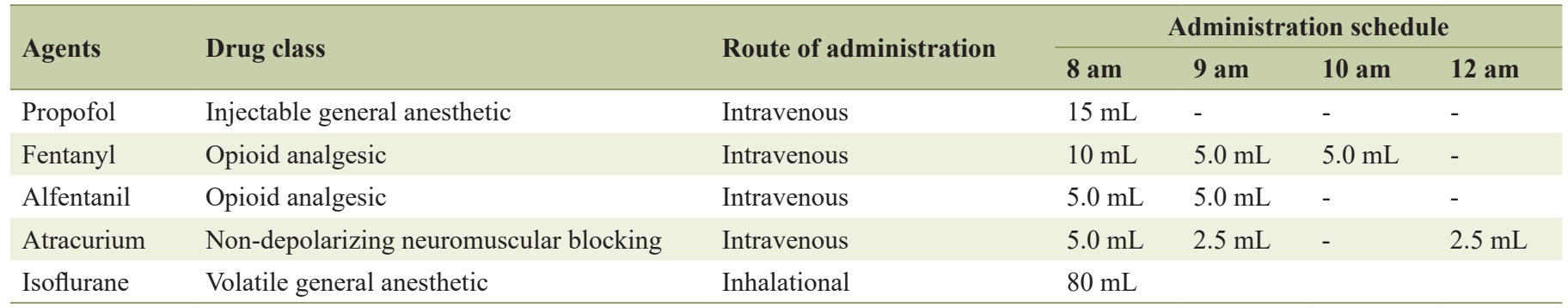

Five hours after the patient arrived at the ICU, he started to present clinical signs of hypermetabolic state, with tremors, excessive sweating, and rapid body temperature increases. In early postoperative, the temperature was being adjusted with an antipyretic (dipyrone) administration. On postoperative days $0(02 / 14), 1(02 / 15), 2(02 / 16)$ and $3(02 / 17)$, nursing reports described an unstable blood pressure, tachycardia and persistent hyperthermia, as shown in Table 2.

In the early postoperative, a chest X-ray was performed, which indicated an elevation of diaphragmatic domes. In addition, the routine tracheal aspiration for intubated patients was carried out and the patient had serosanguinolent secretion.

Some laboratory tests and arterial-blood gas analyses were performed to monitor the patient's clinical conditions (Table $3)$. The blood sugar levels were measured in the pre- and postoperative periods and hyperglycemia was observed in postoperative tests. Postoperative changes in creatine phosphokinase (CPK) concentration were also observed. The first CPK test was carried out on February 15 at 08:26 am, indicating a high CPK concentration, more than 2,380 U/L. After $5 \mathrm{~h}$, a new CPK evaluation was done showing an increase of $164 \%$. The level of serum calcium was normal in the preoperative evaluation; however, the calcium test performed on postoperative day 1 (morning) showed hypocalcemia, whereas in the following postoperative tests the concentration of this ion was returned to the normal level. Serum sodium levels increased from postoperative day 2, while hyperkalemia was observed in the afternoon of postoperative day 1. Serum levels of urea and creatinine were evaluated in the pre- and post-operative periods. Urea and creatinine concentrations were normal in the preoperative tests; however, on postoperative day 1, urea was $78 \%$ higher and creatinine increased more than $350 \%$. On the following postoperative days, both urea and creatinine concentrations kept increasing. Aspartate aminotransferase (AST) and alanine aminotransferase (ALT) enzymes were evaluated in the pre- and postoperative periods. In the preoperative test, the AST and ALT levels were normal. On postoperative day 1 (morning) the AST and ALT levels were approximately 22 and 15 times higher, respectively. A new AST and ALT test were carried out after $5 \mathrm{~h}$ and the values almost doubled.

Two arterial-blood gas analyses were performed on postoperative day 1 . The first arterial-blood gas analysis (08:26 am) showed normal rates, although the partial pressure of oxygen $\left(\mathrm{PaO}_{2}\right)$ increased due to the patient being on mechanical ventilation with pure oxygen. The second arterial-blood gas analysis $(01: 18 \mathrm{pm})$ indicated acidification of the blood $\mathrm{pH}$ and significant changes in both the concentration of base excess and in arterial-blood distribution of gases. In addition, the bicarbonate concentration remained in a normal range and the partial pressure of carbon dioxide $\left(\mathrm{PaCO}_{2}\right)$ increased in both

Table 2. Postoperative Vitals Control According to the Nursing Reports

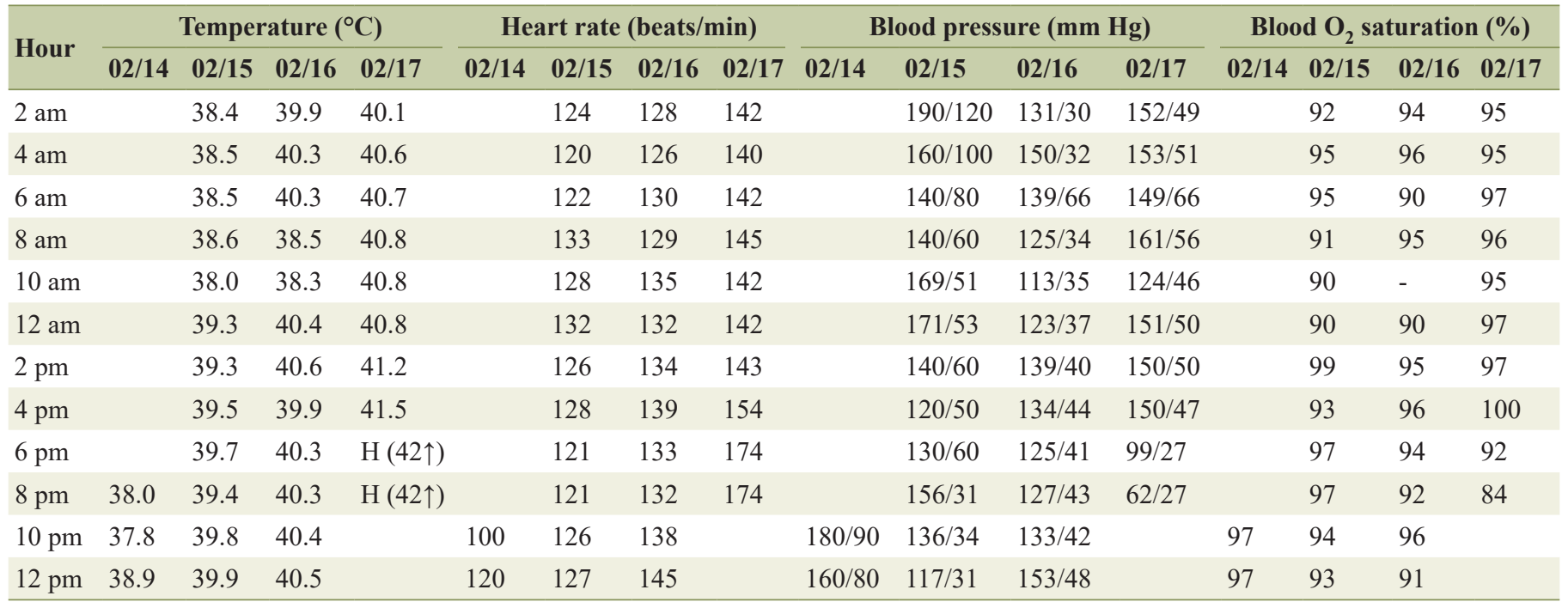


Table 3. Follow-Up Labs and Arterial-Blood Gas Results

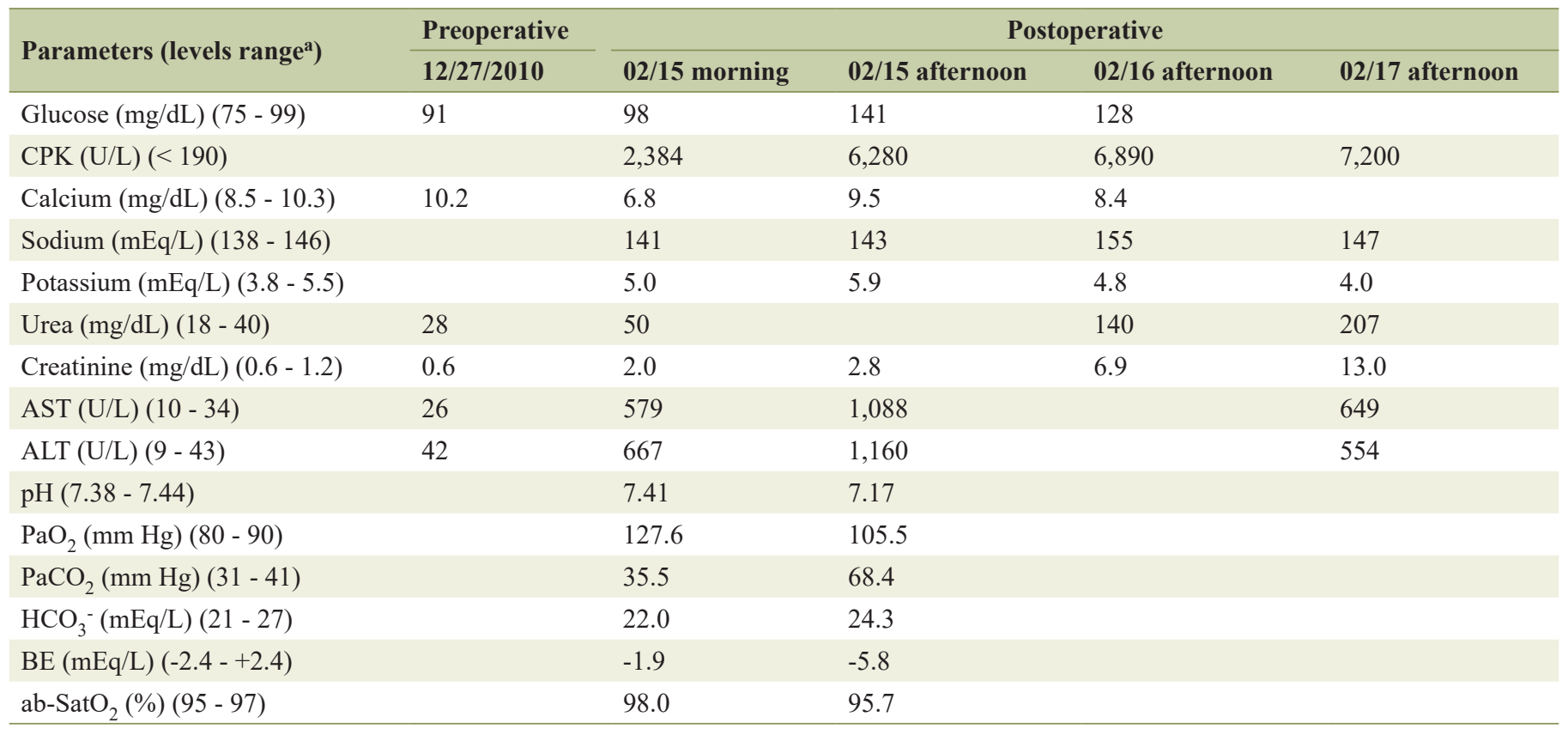

aLevels range for adult men. CPK: creatine phosphokinase; AST: aspartate aminotransferase; ALT: alanine aminotransferase; pH: potential of hydrogen; $\mathrm{PaO}_{2}$ : partial pressure of oxygen; $\mathrm{PaCO}_{2}$ : partial pressure of carbon dioxide; $\mathrm{HCO}_{3}{ }^{-}$: bicarbonate ion; $\mathrm{BE}$ : base excess; ab-SatO ${ }_{2}$ : arterial blood oxygen saturation level.

arterial-blood gas analyses (Table 3).

Preoperative and postoperative blood counts were performed. In the preoperative blood counts, the absolute number of leukocytes was 7,900 $\mathrm{mm}^{3}$ (level range: 4,000 - 10,000 $\mathrm{mm}^{3}$ ). On postoperative day 1 , two blood counts were carried out; the first one showed a significant increase of leukocytes $\left(14,700 \mathrm{~mm}^{3}\right)$, characterizing a leukocytosis. After $2 \mathrm{~h}$, a new leukocyte count was performed and the absolute number decreased to $12,000 \mathrm{~mm}^{3}$. On postoperative day 2 , the absolute number of leukocytes was $13,800 \mathrm{~mm}^{3}$, while the last blood count performed on postoperative day 3 showed 13,000 leukocytes per $\mathrm{mm}^{3}$.

On the postoperative day 1 , an echocardiogram was performed and showed mild symmetric hypertrophy. On the same day, a new chest X-ray was carried out and indicated little pulmonary inspiration, bilateral basal interstitial infiltrate, veiled left diaphragmatic dome, and globose cardiac area.

On the postoperative day 2 , an abdominal ultrasound was carried out and did not indicate any anatomical alteration of the liver, gallbladder, spleen, kidneys, and bladder. In addition, it did not indicate signs of ascites or pleural effusion. A third chest X-ray was performed revealing a veiling of the base of the right lung, cardiomegaly, aortic stretching, permeable costophrenic sinuses and free diaphragmatic domes.

On the postoperative day $3(08: 15 \mathrm{am})$, an urinalysis was accomplished and showed traces of proteinuria, presence of ketones, leukocytes $(17,600 / \mathrm{mL})$, red blood cells $(12,000 / \mathrm{mL})$, and urobilinogen (0.2 UE). On the same day $(3: 50 \mathrm{pm})$, the medical records reported the establishment of multifactorial acute respiratory and renal failures, rhabdomyolysis, systemic inflammatory process and, for the first time, $\mathrm{MH}$ crisis was assumed. At night, nursing reports recorded edema formation of lower limbs, cold and cyanotic extremities, distended abdomen, paleness, and septic shock a few hours before the death of the patient.

The MH diagnosis of L.R.M.S. was conducted less than 5 $\mathrm{h}$ before his death, and the administration of dantrolene sodium was not performed. The patient's exposure to the substances that triggered the crisis was completed when the surgical procedures were over. External body cooling and hyperventilation with pure oxygen were administered in the following postoperative days. Dialysis was done a few hours before the patient's death; however, according to medical reports this procedure caused decompensation of several of the patient's clinical and laboratory parameters. The patient died at 9:20 pm on February 17, 2011 in the Hospital Santa Casa de Jahu.

\section{Discussion}

In $\mathrm{MH}$ crises, there is a persistent increase in the intracytoplasmic calcium concentration. The initial manifestations of a hypermetabolic state induce fast depletion of ATP causing increased carbon dioxide production, increased oxygen demands, respiratory acidosis, and increased temperature [6, $13,14]$. The constant rise in oxygen consumption will lead to a hypoxia and progressive lactic acidosis, while depletion of ATP due to hypermetabolism of skeletal muscle cells will result in metabolic acidosis $[7,13]$. Based on the clinical and lab findings, a late diagnosis of $\mathrm{MH}$ crisis was established for patient L.R.M.S. According to Litman et al (2008) [27], a MH crisis may occur at any time during anesthesia as well as in 
the early postoperative period, although not usually $1 \mathrm{~h}$ after discontinuation of volatile agents. However, in our case the patient displayed initial symptoms of $\mathrm{MH}$ after $11 \mathrm{~h}$ of isoflurane administration, a late postoperative crisis.

Hyperthermia is a key indicator of $\mathrm{MH}$, since the rapid increase in body temperature occurs due to the process of sustained muscle contraction $[3,5,8]$. In the initial postoperative period, the patient's temperature increase was being controlled with the administration of antipyretic. Thereafter, hyperthermia no longer responded with the antipyretic administration, and the patient's body was cooled externally. However, even with measures taken to control the temperature, it continued to increase. Tachycardia is another clinical sign characteristic of $\mathrm{MH}$ and it has been registered since the early postoperative period, as described in Table 2.

Constant muscle contraction causes a decrease in ATP levels and consequent difficulty in muscle relaxation, which explains the masseter rigidity presented by patients during the MH crisis [5, 6, 13, 28]. The patient L.R.M.S. was placed on spontaneous ventilation after the surgical procedure but was maintained with Montgomery T-tube due to his morbid obesity. After being transferred to the ICU, the patient presented a drop in oxygen saturation and needed to be placed on a mechanical respirator, in which he remained until his death. However, it was not observed whether the patient showed masseter rigidity as described in other $\mathrm{MH}$ case reports.

High temperatures (at times over 42 degrees) achieved during $\mathrm{MH}$ crisis, together with the toxins released due to rapid and severe catabolism. It causes profound and acute inflammatory and functional changes of internal organs, leading to changes in the information contained in the blood [7, 8, 2931]. If diagnosed late, $\mathrm{MH}$ causes multiple organ dysfunction (e.g., kidneys, pancreas and liver), disseminated intravascular coagulation (DIC), cardiac dysrhythmias (cardiac arrest), and can progress to multiple organ failure $[3,5,6,17,32]$.

The pre- and early post-operative patient's blood sugar tests were normal. After the afternoon of postoperative day 1, the glucose concentration increased. The hyperglycemia presented by the patient could be due to both a dysfunction of the pancreas caused by the hypermetabolic state and the need of the body to try to supply glucose for the ATP production and, consequently, muscle relaxation.

Creatine phosphokinase is one of the most sensitive indicators of muscular damage. High serum levels of CPK observed after general anesthesia is a strong indicator of an $\mathrm{MH}$ crisis [4]. Expressively high values in the serum CPK concentration indicate damage to contractile cells $[31,33]$, since this enzyme plays an important role in regulation of muscle contraction [34]. Although serum CPK levels were not evaluated during the intraoperative period, our patient presented high levels in all dosages performed in the postoperative period. The increase in serum CPK concentration occurs due to cell lysis, as this enzyme is not able to naturally cross the sarcoplasmic membrane [29, 31, 33].

Calcium is essential for the integrity and structure of cell membranes, proper conduction of electrical stimuli (cardiac and muscular) blood clotting, and bone formation growth [35]. When serum calcium levels decrease, excitability of nerve and muscle cells increases significantly [30]. Given the abundance of calcium in the body, hypocalcemia always means failure in the regulatory mechanisms and can have several causes such as rhabdomyolysis, cardiac arrhythmias, and incessant muscle contractions $[35,36]$. The patient's hypocalcemia detected on postoperative day 1 could be directly related to the renal failure and with increased muscle cell excitability presented.

Sodium is a cation found in high concentration in extracellular fluids [30, 37]. Hypernatremia is always associated with plasma hyperosmolarity and is usually caused by a water deficit (low intake or abnormal losses) or excessive sodium intake $[35,36]$. The patient's hypernatremia observed from postoperative day 2 may be related to renal failure, elevated temperature and hyperventilation.

Potassium is the main intracellular cation and it is critical in many physiological functions, such as in the regulation of neuromuscular excitability and muscle contraction $[35,38]$. Acid-base balance can affect the balance between cellular and extracellular potassium concentration. Metabolic acidosis, hyperglycemia, hyperosmolarity, cell lysis, rhabdomyolysis, and renal failure increase the plasma potassium concentration $[36,38,39]$. Hyperkalemia was noted in our patient on the afternoon of postoperative day 1 . Although the literature describes case reports with contradictory serum potassium concentration, reviews of $\mathrm{MH}$ specify that hyperkalemia is indicative of $\mathrm{MH}$ crisis triggering [1, 3, 7, 8, 12, 17]. According to Mahmood (2018) [40], hyperkalemia can induce fatal cardiac dysrhythmias. The patient's hyperkalemia contributed to the pertinent tachycardia observed from the postoperative period until his death.

Urea is the main nitrogen metabolite derived from the breakdown of proteins by the body, $90 \%$ of which is excreted by the kidneys. Urea is freely filtered by the glomerulus and $40-70 \%$ returns to the plasma through a passive diffusion process, dependent on the urinary flow [41]. Creatinine is a residual product of creatine. The transformation of creatine into creatinine takes place in muscle tissue, in which $1-2 \%$ of free creatine is spontaneously and irreversibly converted to creatinine every day. The amount of creatinine produced is dependent on muscle mass. Creatinine is freely filtered in the glomerulus, too. Unlike urea, $7-10 \%$ of creatinine is actively secreted in the urine $[42,43]$. However, decreased renal function causes increased concentrations of urea and serum creatinine [44]. Lab test results showed a progressive increase in serum levels of urea and creatinine in our patient during the postoperative period, indicating the inability of the kidneys to clear these metabolites and, consequently, the decrease in renal function.

Although our patient's serum myoglobin was not evaluated, the darkening of urine was described in medical reports during the postoperative period. Dark tea or cola-colored urine is caused by an excessive amount of myoglobin in the urine $[31,33]$. In addition, a rhabdomyolysis characterized by high levels of CPK $[29,31]$ resulted in myoglobinuria $[29,45]$ observed during the patient's urinalysis.

The leukocytosis observed in the blood test and the presence of leukocytes in the urine analysis are indicative of an infection. The presence of leukocytes in urine reinforced the suspicion of acute renal injury due to myoglobinuria [46]. As a result of rhabdomyolysis (generalized inflammatory process), 
there was an increase in circulating leukocytes. Kidney damage caused leukocyte migration to combat this inflammatory response. In addition, the intestinal bacterial proliferation significantly increased due to the high and persistent temperature. This bacterial growth caused distension of the intestine and the intra-intestinal pressure became markedly high and triggered a phenomenon called bacterial translation. However, a large amount of bacteria was pushed into blood circulation and triggered a defensive rise in leukocytosis.

AST enzyme is present inside several tissues of the body; the highest concentrations are in the heart and kidneys, but the enzyme is also produced in the liver and skeletal muscles. ALT is found almost exclusively in liver cells and is responsible for the metabolism of some proteins such as L-aspartate, alpha-ketoglutarate, and alanine. Quantification of AST and ALT serum levels is performed to evaluate potential liver damage. High AST level indicates trauma or muscle damage and is a quite common finding in rhabdomyolysis. The significant increase in serum AST and ALT concentrations observed in the postoperative exams of our patient may be related to skeletal muscle injuries due to exhaustive muscle contraction.

The patient's hyperglycemia, hypernatremia, hyperkalemia, and metabolic acidosis contributed to the blood $\mathrm{pH}$ reduction recorded by arterial-blood gas analysis.

Respiratory acidosis is characterized by an elevation of $\mathrm{PaCO}_{2}$, with or without compensatory increase in bicarbonate ions $\left(\mathrm{HCO}_{3}^{-}\right)$, plus $\mathrm{pH}$ acidification [47]. The causes are associated with decreased respiratory rate, inspired volume (hypoventilation) and blood oxygen saturation due to muscle diseases, respiratory or neurological conditions [37].

Specific situations such as those that occur during the $\mathrm{MH}$ crisis cause an increase in temperature, and blood $\mathrm{pH}$ acidification with a decrease in the affinity of hemoglobin for oxygen. Although there is an increase in both $\mathrm{PaO}_{2}$ and oxygen supply as a result of mechanical ventilation with pure oxygen, the affinity of oxygen for hemoglobin is reduced. The increase in carbon dioxide production due to continuous muscle contraction causes an increase in carbon dioxide concentration and, consequently, the $\mathrm{PaCO}_{2}$. In addition, the increase in carbon dioxide concentration increases the association between carbon dioxide and water, forming carbonic acid $\left(\mathrm{H}_{2} \mathrm{CO}_{3}\right)$. Carbonic acid, by the action of carbonic anhydrase, dissociates into bicarbonate ions and hydrogen ions, further decreasing blood $\mathrm{pH}[30,37]$.

Throughout the postoperative period, even with constant oxygen supply, the patient's blood $\mathrm{O}_{2}$ saturation was low (Table 2). The high temperature, acidification of blood $\mathrm{pH}$, and the increased $\mathrm{PaCO}_{2}$ contributed to decrease the affinity of hemoglobin for oxygen. During the $\mathrm{MH}$ crisis, although the decrease in hemoglobin affinity for oxygen caused the incorporation of hydrogen ions in hemoglobin, the blood $\mathrm{pH}$ acidification occurred both by metabolic acidosis and by increasing the carbon dioxide concentration.

The patient's arterial-blood gas analysis showed blood $\mathrm{pH}$ acidification and increase in $\mathrm{PaO}_{2}$ and in $\mathrm{PaCO}_{2}$. The patient's bicarbonate ion concentration was in normal range, but the base excess concentration indicated a deficit of bases dissolved in his blood during the postoperative period.

The increase in the occurrence of dyspnea in obese pa- tients is evident and its intensity is directly proportional to the body mass index [48]. The patient's medical history included obesity grade III and severe obstructive sleep apnea. During the postoperative period, the patient remained lying down, in high decubitus, with a distended abdomen, making breathing difficult. The patient had low blood $\mathrm{O}_{2}$ saturation even under mechanical ventilation with hyperventilation of pure oxygen. However, chest X-rays and ultrasound ruled out a possible pleural effusion or pneumothorax due to mechanical ventilation. In addition, atelectasis due to intubation, one of the most common respiratory complications after surgery, was discarded.

Zutt et al (2014) [31] suggest that complementary cardiac assessments should be performed when the patient has electrolyte disturbances during the $\mathrm{MH}$ crisis. On postoperative days 2 and 3, chest X-rays were carried out and indicated globose cardiac area and cardiomegaly, respectively. On the postoperative day 1 , an echocardiogram was performed to evaluate anatomical and functional aspects of our patient's heart. The echocardiogram indicated mild symmetrical hypertrophy as an adaptive response of the heart to arterial hypertension presented by the patient during the postoperative period, as described in Table 2.

As soon as the MH crisis is diagnosed, the patient's exposure to the substances that triggered the crisis must be stopped and the administration of dantrolene sodium must be initiated immediately $[5,8,11,17,22]$. Dantrolene sodium is the only clinically available drug for the specific MH treatment [23]. Several case reports have different descriptions with or without the dantrolene addition. In some cases, dantrolene was administered immediately after the $\mathrm{MH}$ crisis triggering, both during the intraoperative $[4,13,40,49,50]$ and postoperative $[32,51,52]$ periods and all patients were discharged from the hospital in stable conditions. Late addition of dantrolene is also reported in intra- and postoperative $\mathrm{MH}$ cases with different results, and some were fatal, while others had no additional complications $[2,45,53,54]$. On the other hand, there were related intra- $[28,55]$ and postoperative [54] $\mathrm{MH}$ cases in which dantrolene was not administrated due to non-availability of the drug in the hospital. Iqbal et al (2017) [28] reported the clinical signs and laboratory parameters altered by the $\mathrm{MH}$ crisis were reversed with internal (ice cold saline intravenously) and external (ice packs and cold towels over the body) cooling, and the patient had full recovery before being discharged. Pan et al (2016) [54], in the case report III, described that the inhalation anesthetic was not used in the operation, but the body temperature rose slowly during the postoperative period and, after 2 days, the patient was in critical condition. Meanwhile, Lazraq et al (2019) [55] and Pan et al (2016) (case report I) [54] reported that patients had persistent high fever and died despite all the resuscitation procedures administered. Unfortunately, in our case, dantrolene could not be used because it was not available at the hospital or in other hospitals in nearby cities and the patient died. In Sao Paulo, the Law 10.781, published on March 9, 2001, provides for the state policy for the prevention, diagnosis and treatment of $\mathrm{MH}$ and the second Article describes that all public or private health services in the state of Sao Paulo, Brazil must have appropriate medications to fight the disease, especially dantrolene sodium.

Larach et al (1994) [56] proposed a clinical grading scale 
(CGS) to predict MH susceptibility and help to confirm the $\mathrm{MH}$ diagnosis after halogenated volatile inhalational anesthetic administration. Based on the Larach scale, our patient had the almost certain probability to developed $\mathrm{MH}$. He was rated grade 6, the highest grade with a score higher than 50 .

In 1998, Richthofen et al [57] compared the results obtained with the use of the CGS with the results obtained in carrying out the in vitro contracture test (IVCT) and concluded that the CGS cannot replace IVCT. However, the indication of prediction for $\mathrm{MH}$ susceptibility through CGS can guide the patient and/or their family members in IVCT carried out to confirm the $\mathrm{MH}$ diagnosis/susceptibility.

The CHCT was carried out on the patient's brother to confirm the MH diagnosis. G.H.M.S, 21-year-old, born in Jau, SP, Brazil and never underwent halogenated anesthesia, was performed the CHCT at the Malignant Hyperthermia Diagnostic Center of the Federal University of Rio de Janeiro, in August 2011. The CHCT indicated a contracture of $1.27 \mathrm{~g}$ in a muscle strip exposed to caffeine at $2 \mathrm{mM}$ and the results were considered positive indicating MH susceptibility [24]. Almeida da Silva et al (2019) [1] evaluated the profile of MH susceptibility reports confirmed with muscle contracture test in Brazil. In the period 1997 - 2010, approximately $80 \%$ of the individuals submitted to CHCT presented positive results for MH susceptibility [1].

The patient's sister underwent the same surgical procedure, with the same doctor and in the same hospital 2 years earlier and did not present any complications during the intraoperative and postoperative periods. In addition, she had undergone three other surgical procedures with halogenated anesthesia without complications. The literature findings described that the $\mathrm{MH}$ crisis can occur during the first or even after the exposure to a triggering agent due to incomplete penetrance and variable expression of the genes encoding the $\mathrm{MH}$ disease $[8,19,20,58,59]$.

The delayed diagnosis of $\mathrm{MH}$ crisis reported here could be associated with the onset of clinical symptoms and changes in laboratory parameters observed in the late postoperative period, and with the low clinical incidence of $\mathrm{MH}$. For instance, L.R.M.S. was the first patient diagnosed with $\mathrm{MH}$ at Hospital Santa Casa de Jahu (and in Jau city, SP). However, this $\mathrm{MH}$ episode and the patient's brother CHCT results should be reported on pre-anesthetic evaluations of the patient's family members before undergoing procedures under general anesthesia to prevent $\mathrm{MH}$ crisis.

\section{Conclusions}

The detailed report of the development of the $\mathrm{MH}$ episode triggered by halogenated anesthetic during bariatric surgery allowed us to describe the severity and lethality of this hypermetabolic syndrome. The dissemination and accessibility of data on $\mathrm{MH}$ are of high relevance for the medical, academic and scientific communities. The need to understand in detail the clinical and the pathophysiological, biochemical and biophysical mechanisms associated with $\mathrm{MH}$ is of fundamental practical importance in preventing and reversing an $\mathrm{MH}$ crisis.

Knowledge of the carrier's situation allows patients and family members to alert the medical team if there is a need to perform any surgical procedure, thus avoiding the use of halogenated anesthetics. In addition, it is essential that dantrolene sodium be included in emergency medications that are mandatory in all operating rooms. However, knowledge of the symptoms, an early diagnosis and an adequate treatment can prevent the death of patients in $\mathrm{MH}$ crisis.

\section{Acknowledgments}

The authors thank Dr. Itamar Trindade Neves Epifanio and Prof. Dr. Victor L. Davidson for their valuable scientific contribution. The authors also thank Francis Joseph Alves, Anthony Pastore and Lyman (Tony) Antoine Scribner III for their help in correcting the work.

\section{Financial Disclosure}

None to declare.

\section{Conflict of Interest}

None to declare.

\section{Informed Consent}

Informed consent was obtained from the patient's family as well as authorization to use and disclose protected health information.

\section{Author Contributions}

The authors PEAO, GHMS and DPMS fit all four criteria recommended by the ICMJE: 1) Contributed substantially to the conception or design of the work as well as to the acquisition, organization, analysis, and interpretation of all data set out in this manuscript; 2) Contributed to the preparation of the work and reviewed it critically and in detail; 3) Approved the final version of the manuscript to be published; and 4) Agreed to be accountable for all aspects of the work in ensuring that questions related to the accuracy or integrity of any part of the work are appropriately investigated and resolved.

\section{Data Availability}

All data described in this case report are available and can be requested from the corresponding author.

\section{References}

1. Almeida da Silva HC, Ferreira G, Rodrigues G, Santos 
JMD, Andrade PV, Hortense A, Vaz Perez M, et al. [Profile of malignant hyperthermia susceptibility reports confirmed with muscular contracture test in Brazil]. Rev Bras Anestesiol. 2019;69(2):152-159.

2. Enid L, Fino E, Antonia L, Villanueva C, Mayela L, Gonzales T. Diagnostico de Hipertermia maligna: reporte de caso Diagnostic of Malignant hyperthermia: a case presentation. Rev Med Hondur. 2019;87.

3. Ali SZ, Taguchi A, Rosenberg H. Malignant hyperthermia. Best Pract Res Clin Anaesthesiol. 2003;17(4):519533.

4. Fernandes CR, Azevedo DM, Gomes JM, Goncalves BP, Coelho GR, Vasconcelos JB, Garcia JH. Malignant hyperthermia in a liver transplant patient: a case report. Transplant Proc. 2007;39(10):3530-3532.

5. Kim KSM, Kriss RS, Tautz TJ. Malignant Hyperthermia: A Clinical Review. Adv Anesth. 2019;37:35-51.

6. Ellinas H, Albrecht MA. Malignant Hyperthermia Update. Anesthesiol Clin. 2020;38(1):165-181.

7. Amare M, Wilson M. Malignant hyperthermia. Anaesth Intensive Care Med. 2020:1-5.

8. Correia AC, Silva PC, da Silva BA. Malignant hyperthermia: clinical and molecular aspects. Rev Bras Anestesiol. 2012;62(6):820-837.

9. Costa WP da, Menezes TM, Bomfa GGN, Souza R de L e, Menezes PJM, Motta LR. Malignant hyperthermia: reviewing important aspects. Rev Medica Minas Gerais. 2017;27(Supl 2):67-73.

10. Riazi S, Kraeva N, Hopkins PM. Malignant Hyperthermia in the Post-Genomics Era: New Perspectives on an Old Concept. Anesthesiology. 2018;128(1):168-180.

11. Louis CF, Balog EM, Fruen BR. Malignant hyperthermia: an inherited disorder of skeletal muscle $\mathrm{Ca}+$ regulation. Biosci Rep. 2001;21(2):155-168.

12. Hopkins PM, Ruffert H, Snoeck MM, Girard T, Glahn KP, Ellis FR, Muller CR, et al. European Malignant Hyperthermia Group guidelines for investigation of malignant hyperthermia susceptibility. Br J Anaesth. 2015;115(4):531-539.

13. Gibbs IC, Fadahunsi O, Reid N, Bonnick AM. Malignant Hyperthermia: A Case Report in a Trauma Patient. J Oral Maxillofac Surg. 2019;77(1):54-58.

14. Smith JL, Tranovich MA, Ebraheim NA. A comprehensive review of malignant hyperthermia: Preventing further fatalities in orthopedic surgery. J Orthop. 2018;15(2):578-580.

15. Lorenzon NM, Beam KG. Calcium channelopathies. Kidney Int. 2000;57(3):794-802.

16. Jurkat-Rott K, Lehmann-Horn F. Muscle channelopathies and critical points in functional and genetic studies. J Clin Invest. 2005;115(8):2000-2009.

17. Long M, Ross J. Malignant hyperthermia. J Radiol Nurs [Internet]. 2017;36(3):152-157.

18. Sene ES de O, Viana TG, Catunda KA, Bittar E. Estrategia educativa com profissionais de enfermagem sobre hipertermia maligna em um centro cirurgico cardiovascular. Rev SOBECC. 2020;25(1):42-49.

19. Larach MG, Gronert GA, Allen GC, Brandom BW, Lehman EB. Clinical presentation, treatment, and complica- tions of malignant hyperthermia in North America from 1987 to 2006. Anesth Analg. 2010;110(2):498-507.

20. Gupta PK, Hopkins PM. Diagnosis and management of malignant hyperthermia. BJA Educ [Internet]. 2017;17(7):249-254.

21. Glahn KP, Ellis FR, Halsall PJ, Muller CR, Snoeck MM, Urwyler A, Wappler F, et al. Recognizing and managing a malignant hyperthermia crisis: guidelines from the European Malignant Hyperthermia Group. Br J Anaesth. 2010;105(4):417-420.

22. Harrison GG. The prophylaxis of malignant hyperthermia by oral dantrolene sodium in swine. Br J Anaesth. 1977;49(4):315-317.

23. Krause T, Gerbershagen MU, Fiege M, Weisshorn R, Wappler F. Dantrolene - a review of its pharmacology, therapeutic use and new developments. Anaesthesia. 2004;59(4):364-373.

24. Rosenberg H, Antognini JF, Muldoon S. Testing for malignant hyperthermia. Anesthesiology. 2002;96(1):232237.

25. Hernandez JF, Secrest JA, Hill L, McClarty SJ. Scientific advances in the genetic understanding and diagnosis of malignant hyperthermia. J Perianesth Nurs. 2009;24(1):19-31; quiz 32-14.

26. Ellis FR, Harriman DG, Keaney NP, Kyei-Mensah K, Tyrrell JH. Halothane-induced muscle contracture as a cause of hyperpyrexia. Br J Anaesth. 1971;43(7):721722.

27. Litman RS, Flood CD, Kaplan RF, Kim YL, Tobin JR. Postoperative malignant hyperthermia: an analysis of cases from the North American Malignant Hyperthermia Registry. Anesthesiology. 2008;109(5):825-829.

28. Iqbal A, Badoo S, Naqeeb R. A case report of suspected malignant hyperthermia where patient survived the episode. Saudi J Anaesth. 2017;11(2):232-235.

29. Giannoglou GD, Chatzizisis YS, Misirli G. The syndrome of rhabdomyolysis: Pathophysiology and diagnosis. Eur J Intern Med. 2007;18(2):90-100.

30. Guyton A, Hall J. Fisiologia medica [Internet]. Internal medicine (Tokyo, Japan). 2006;37:1151

31. Zutt R, van der Kooi AJ, Linthorst GE, Wanders RJ, de Visser M. Rhabdomyolysis: review of the literature. Neuromuscul Disord. 2014;24(8):651-659.

32. Syed S, Ansari M, Nivarthi B, Patel N, Farooq K, Kaur J, et al. A rare presentation of malignant hyperthermia in a patient with poliomyelitis. J Med Cases. 2018;9(7):236237.

33. Cabral BMI, Edding SN, Portocarrero JP, Lerma EV. Rhabdomyolysis. Dis Mon. 2020;66(8):101015.

34. Saks VA, Rosenshtraukh LV, Smirnov VN, Chazov EI. Role of creatine phosphokinase in cellular function and metabolism. Can J Physiol Pharmacol. 1978;56(5):691706.

35. Evora PRB, Reis CL dos, Ferez MA, Conte DA, Garcia LV. Disturbios Do Equilibrio Hidroeletrolitico E Do Equilibrio Acidobasico - Uma Revisao Pratica. Med (Ribeirao Preto Online). 1999;32(4):451.

36. Barbosa AP, Sztajnbok J. Disturbios hidroeletroliti$\cos$ Fluid and electrolyte disorders. J Pediatr (Rio J). 
$1999 ; 75: 223-233$.

37. Silverthorn D. Fisiologia humana: uma abordagem integrativa [Internet]. Exercise and Sport Sciences Reviews. 2017:1.

38. Lehnhardt A, Kemper MJ. Pathogenesis, diagnosis and management of hyperkalemia. Pediatr Nephrol. 2011;26(3):377-384.

39. Dutra V de F, Tallo FS, Rodrigues FT, Vendrame LS, Lopes RD, Lopes AC. Desequilibrios hidroeletroliticos na sala de emergencia. Rev Bras Clin Med Sao Paulo. 2012;10(5):410-419.

40. Mahmood S. A case report of malignant hyperthermia in a young male veteran diagnosed with an early rise of ETCO2 during shoulder arthroscopy. Juniper Online J Case Stud. 2018;5(5):1-3.

41. Dusse LMS, Rios DRA, Sousa LPN, Moraes RMM e S, Domingueti CP, Gomes KB. Biomarkers of renal function: what is currently available? Rev Bras Analises Clinicas. 2017;49(1):41-51.

42. Kirsztajn BM, Bastos MG, et al. 2004;74-87.

43. Sodre FL, Costa JCB, Lima JCC. Avaliacao da funcao e da lesao renal: Um desafio laboratorial. J Bras Patol e Med Lab. 2007;43(5):329-337.

44. Peres LA, Cunha Junior AD, Schafer AJ, Silva AL, Gaspar AD, Scarpari DF, Alves JB, et al. Biomarkers of acute kidney injury. J Bras Nefrol. 2013;35(3):229-236.

45. Forrest KM, Foulds N, Millar JS, Sutherland PD, Pappachan VJ, Holden S, Mein R, et al. RYR1-related malignant hyperthermia with marked cerebellar involvement - a paradigm of heat-induced CNS injury? Neuromuscul Disord. 2015;25(2):138-140.

46. Petejova N, Martinek A. Acute kidney injury due to rhabdomyolysis and renal replacement therapy: a critical review. Crit Care. 2014;18(3):224.

47. Carlotti APDCP. A clinical approach to acid-base disorders. Med. 2012;45(2):244-262.

48. Stirbulov R. Respiratory repercussions of obesity. J Bras Pneumol. 2007;33(1):vii-viii.

49. Vasconcelos JVRM, Suguita FH, Cardoso AR BA. Hi- pertermia maligna em paciente submetida a correcao de gigantomastia: relato de caso malignant hyperthermia in patient submitted to gigantomastia correction: case report. Rev Soc Bras Cir Plast. 2007;22(2):126-130.

50. Cornelius BW, Dib SO, Dowdy RA, Horton CK, Frimenko K, Mansour S, Sharkh FA, et al. Malignant hyperthermia: a case study in the dental ambulatory surgery setting. Anesth Prog. 2019;66(4):202-210.

51. Osman BM, Saba IC, Watson WA. A case report of suspected malignant hyperthermia: how will the diagnosis affect a patient's insurability? Case Rep Anesthesiol. 2018;2018:1-5.

52. Plurad D, Blaschke G, Jones S, Pfeiffer J. A case of malignant hyperthermia in a child encountered during a humanitarian assistance mission to the Philippines. Mil Med. 2008;173(8):805-808.

53. Lee YS, Kim WY, Lee SH, Baek SM, Ok SJ, Kim JH, Park YC. A case of malignant hyperthermia during anesthesia induction with sevoflurane -A case report. Korean J Anesthesiol. 2010;59(Suppl):S6-8.

54. Pan T, Ji W, Nie M, Li Y. Clinical treatment of malignant hyperthermia in three cases. Exp Ther Med. 2016;12(5):2881-2884.

55. Lazraq M, Dafir A, Bensaid A, Miloudi Y, Alharrar N. Malignant hyperthermia: a case report. J Emergency, Crit Care Diagnostic Manag Open. 2019;2(1):1-2.

56. Larach MG, Localio AR, Allen GC, Denborough MA, Ellis FR, Gronert GA, Kaplan RF, et al. A clinical grading scale to predict malignant hyperthermia susceptibility. Anesthesiology. 1994;80(4):771-779.

57. von Richthofen V, Wappler F, Scholz J, Fiege M, Schulte am Esch J. [Evaluation of malignant hyperthermia episodes with the Clinical Grading Scale]. Anasthesiol Intensivmed Notfallmed Schmerzther. 1998;33(4):244-249.

58. Strazis KP, Fox AW. Malignant hyperthermia: a review of published cases. Anesth Analg. 1993;77(2):297-304.

59. Rosenberg H, Davis M, James D, Pollock N, Stowell K. Malignant hyperthermia. Orphanet J Rare Dis. 2007;2(1):1-14. 